\title{
Microencapsulation of nisin in alginate-cellulose nanocrystal (CNC) microbeads for prolonged efficacy against Listeria monocytogenes
}

\author{
Tanzina Huq · Bernard Riedl · Jean Bouchard · \\ Stephane Salmieri $\cdot$ Monique Lacroix
}

Received: 2 June 2014/Accepted: 3 September 2014/Published online: 21 September 2014

(C) Springer Science+Business Media Dordrecht 2014

\begin{abstract}
The present study was undertaken to develop edible nisin-microencapsulated beads in order to inhibit growth of Listeria monocytogenes in readyto-eat (RTE) ham. Different concentrations of nisin $(16,31$, and $63 \mu \mathrm{g} / \mathrm{ml})$ were microencapsulated into alginate-cellulose nanocrystal beads. Microencapsulation kept the available nisin $(63 \mu \mathrm{g} / \mathrm{ml})$ content 20 times greater compared with free nisin $(63 \mu \mathrm{g} / \mathrm{ml})$ during 28 days of storage at $4{ }^{\circ} \mathrm{C}$. Results showed that $63 \mu \mathrm{g} / \mathrm{ml}$ microencapsulated nisin exhibited $31.26 \mu \mathrm{g} /$ $\mathrm{ml}$ available nisin content after 28 days of storage at $4{ }^{\circ} \mathrm{C}$, whereas there was no available nisin content left for free nisin. Cooked ham slices were then coated by the microencapsulated nisin beads, inoculated with $L$ monocytogenes [ $\sim 3$ log colony-forming units $(\mathrm{CFU}) / \mathrm{g}]$, and stored at $4{ }^{\circ} \mathrm{C}$ under vacuum packaging for 28 days. The beads containing 16, 31, and $63 \mu \mathrm{g} /$
\end{abstract}

$\mathrm{ml}$ nisin significantly $(P \leq 0.05)$ reduced the $L$ monocytogenes counts by $2.65,1.50$, and $3.04 \mathrm{log} \mathrm{CFU} / \mathrm{g}$ after 28 days of storage compared with free nisin. Furthermore, microencapsulated nisin beads did not change the physicochemical properties ( $\mathrm{pH}$ and color) of RTE ham during storage.

Keywords Microencapsulation - Nisin -

Microbeads - Listeria monocytogenes - RTE meat Cellulose nanocrystals

\section{Introduction}

The safety of ready-to-eat (RTE) meat products is of high concern due to the likelihood of contamination by 